\title{
Intravascular ultrasound imaging of angiographically normal coronary arteries: a prospective study in vivo
}

Junbo Ge, Raimund Erbel, Thomas Gerber, Günter Görge, Lothar Koch, Michael Haude, Jürgen Meyer

\section{Abstract}

Intravascular ultrasound imaging (IVUS) was performed to elucidate the discrepancy between clinical history and angiographic findings and to measure the diameter and area of the lumen of the normal left coronary artery in 55 patients who presented with chest pain but had normal coronary angiograms. The left coronary artery (LCA) was scanned with a $4 \cdot 8 \mathrm{~F}, 20 \mathrm{MHz}$ mechanically rotated ultrasound catheter at 413 sites. Atherosclerotic lesions were identified at 72 $(17 \%)$ sites in 25 patients. The mean (SD) (range) plaque area was $5.55(3.56) \mathrm{mm}^{2}$ (2-26 $\mathrm{mm}^{2}$ ) and it occupied $28.8(9 \cdot 6) \%$ (13-70\%) of the coronary cross sectional area. Calcification was detected at 24 (33\%) atherosclerotic sites in nine patients. The correlation coefficients for the lumen dimensions measured at normal sites by IVUS and by angiography were $r=0.93(\mathrm{SEE}=0.43) \mathrm{mm}$ for lumen diameter and $r=0.89(S E E=4.27) \mathrm{mm}^{2}$ for lumen area (both $p<0.001$ ). 16 of the 30 patients in whom no atherosclerotic plaques were detected in the LCA lumen by IVUS had no risk factors of coronary artery disease. The cross sectional area of 90 consecutive images of left main coronary artery (LMCA), proximal left anterior descending coronary artery (proximal LAD), and mid LAD was measured in these 16 subjects. The mean (SEM) areas at end diastole were LMCA $17.33(7.98) \mathrm{mm}^{2}$; proximal LAD 13.56 $(5 \cdot 85) \mathrm{mm}^{2}$; mid LAD $9.75(4.67) \mathrm{mm}^{2}$. During the cardiac cycle the cross sectional area changed by $10 \cdot 2(4 \cdot 0) \%$ in the LMCA, by $8.3(4 \cdot 7) \%$ in the proximal LAD, and by $9.8(4 \cdot 0) \%$ in the mid LAD. In 11 patients with plaques the change in cross sectional area in plaque segments $(5 \cdot 8(3 \cdot 1) \%)$ was significantly lower than in the segments from patients without plaques $(p<0.001)$. Lumen area reached a maximum in early diastole rather than in late diastole.

IVUS can image atherosclerotic lesions that are angiographically silent; it also provides detailed information about plaque characteristics. The variation in coronary cross sectional area during the cardiac cycle should not be ignored during quantitative analysis. Maximum dimensions in normal segments are reached in early diastole. Further studies are needed to clarify the clinical significance of atherosclerosis detected by IVUS in patients presenting with chest pain but normal coronary angiography.

(Br Heart f 1994;71:572-578)

Cardiologists have relied on contract coronary angiography to evaluate vascular morphology and architecture in patients with coronary heart disease. But angiography can only define the contour of the vessel lumen and major structural alterations or abnormalities of the vessels. ${ }^{1-3}$ Even with biplane imaging, angiography gives little information on arterial wall thickness and the three dimensional configuration of the vessel lumen. Furthermore, discrepancies between cineangiographic and postmortem findings are considerable, showing that complex and eccentric coronary atherosclerotic lesions are often not identified by angiography. ${ }^{45}$

There has been considerable interest in intravascular ultrasound imaging (IVUS), a catheter-based ultrasound technique, because it offers in vivo information on vascular anatomy, physiology, and pathology that has not been available until now. ${ }^{6-10}$ Preliminary in vitro and in vivo studies showed that IVUS was a safe, feasible, and accurate method for evaluating vascular morphology. ${ }^{11-14}$ Correlations for assessing vessel wall thickness, lumen area, lumen diameter, and perimeter in vitro were excellent, ${ }^{11-14}$ but results in vivo remain controversial. ${ }^{9-11} 15$

The purposes of this study were: to compare IVUS with coronary angiography in the evaluation of the morphology of the left coronary artery (LCA); to assess the accuracy and feasibility of IVUS for measuring the dimensions of angiographically normal coronary arteries; to determine the dimensions of the normal LCA; and to study changes in the dimensions of the normal LCA during the cardiac cycle.

Patients and methods

PATIENTS

We studied 55 consecutive patients $(28$ men 
and 27 women aged (mean (SD)) 42-70 years $(55.9(7 \cdot 2))$ who underwent diagnostic coronary angiography for suspected ischaemic heart disease and were found to have angiographically normal coronary arteries. Each gave their informed consent to intracoronary ultrasound imaging. After coronary angiography each patient was given $3000 \mathrm{IU}$ of intracoronary heparin. An $8 \mathrm{~F}$ or a $9 \mathrm{~F}$ guiding catheter was used to position the ultrasound catheter for IVUS imaging. A 0.014 inch guidewire was placed in the left anterior descending coronary artery (LAD) and we advanced the imaging catheter over the wire using a monorail technique to obtain coaxial images. The IVUS catheter was then drawn back slowly while the images were recorded in real time and stop frames (every 3-5 mm). The position of the IVUS probe was recorded on an $x$ ray film at the points at which the stop frame IVUS images were taken.

\section{INTRAVASCULAR ULTRASOUND DEVICE}

We used an IVUS catheter with a $4 \cdot 8 \mathrm{~F}$ catheter sheath and a $20 \mathrm{MHz}$ ultrasound transducer inside the catheter (Sonicath, Boston Scientific Corporation, Watertown, MA, USA). The transducer was mechanically rotated within the catheter at $900 \mathrm{rpm}$ to provide cross sectional images on a $512 \times 512$ pixel ultrasound diagnostic imaging console (Diasonics, Milpitas, CA, USA). A simultaneous electrocardiogram was recorded below the IVUS images. The axial resolution of the catheter is about $150 \mu \mathrm{m}$ and the lateral resolution is about $300 \mu \mathrm{m}$. The images were recorded on half inch S-VHS videotape for off-line analysis.

IVUS IMAGE ANALYSIS

All the IVUS images were digitised ( 32 frames in series) into a $512 \times 512$-pixel matrix by an image processing computer (ECHO-COM, PPG Hellige, Freiburg, Germany). The images were stored on a one gigabyte erasable optical disk (Maxtor, The Netherlands). These images were reviewed to identify the best frame, which was magnified by the built-in zoom function to measure the lumen diameter and cross sectional area.

Sixteen of the patients we examined, were regarded as truly normal subjects (see results). Ninety consecutive IVUS images of the LMCA, of the proximal LAD, and of the mid LAD were digitised onto a $256 \times 256$ pixel format. A semi-automatic software program based on PV-wave (Precision Visuals, Boulder, CO, USA) was developed for the evaluation of the luminal area. Digitised images were evaluated on a SUN SPARC-2 workstation (Mountain View, CA, USA). The program shifted frames to compensate for catheter movement caused by cardiac motion. A region of interest including both the lumen and the vessel wall was defined interactively. Both the vessel wall and lumen were segmented by thresholding. After segmentation the contours of the lumen were superimposed on the original images. If there was a mismatch, for example, caused by signal dropout, we repeated the procedure after correcting the threshold or region of interest. The area of the segmented lumen was measured after the removal of the catheter and guidewire artefact. We displayed the pulsatile variation of the cross sectional area of the lumen over at least three cardiac cycles. For each cardiac cycle we measured the maximum area, minimum area, and ECG-triggered end diastolic area. The IVUS images of the plaque segment in 11 patients were suitable for analysis of the cross sectional area. These values were compared with those of the normal segments in $\mathbf{1 6}$ controls.

\section{ANGIOGRAPHIC MEASUREMENT}

The cineangiogram was projected onto a $20 \times 28 \mathrm{~cm}$ screen by an angiogram projection system (CAB-35B, Weinberger, Zürich, Switzerland). The LAD was magnified and drawn. The positions at which the IVUS images had been taken were then superimposed on the drawing. The diameter of the contrast free guiding catheter $(8 \mathrm{~F}=2.67 \mathrm{~mm}$, $9 \mathrm{~F}=3 \mathrm{~mm}$ ) was used for calibration; the diameter of the vessel was measured by an image processing computer (Kontron, Cardio-500, Germany). The luminal area was calculated as:

$$
\mathrm{A}=1 / 4 . \pi \cdot \mathrm{D}^{2}
$$

where $A$ is lumen area and $D$ is lumen diameter.

\section{STATISTICAL ANALYSIS}

The values of lumen dimensions were presented as mean (1 SD). We used linear regression and correlation coefficients to examine the relation between the lumen dimensions measured on the IVUS images and those measured by angiography. We also calculated inter and intra observer variation for 30 IVUS images. We used the Paired $t$ test to evaluate the variation in the cross sectional area during the cardiac cycle.

\section{Results}

\section{MORPHOLOGICAL OBSERVATIONS}

We examined 413 sites in 55 patients. IVUS images of normal coronary segment showed a circular or eliptical lumen with a smooth surface (fig 1). We identified atherosclerotic plaques at $72(17 \%)$ sites in $25(45 \%)$ patients. The plaque area was 5.55 $(3.56) \mathrm{mm}^{2}\left(2-26 \mathrm{~mm}^{2}\right)$, and it occupied $28 \cdot 8$ $(9 \cdot 6) \%(13-70 \%)$ of the coronary cross sectional area. Calcification was detected at 24 (33\%) sites in nine patients, (fig 2). Most of the plaques ( $84 \%$ ) were eccentric (fig 3). None of the patients had obvious stenoses on the coronary angiograms but in one patient with typical angina and a positive exercise ECG, pressure at the catheter tip dropped when it was placed in the left main coronary ostium. There were no obvious abnormalities on angiograms in any projection. IVUS was performed immediately after the angiography in examination during which ischaemic ECG changes occurred. IVUS showed a large 


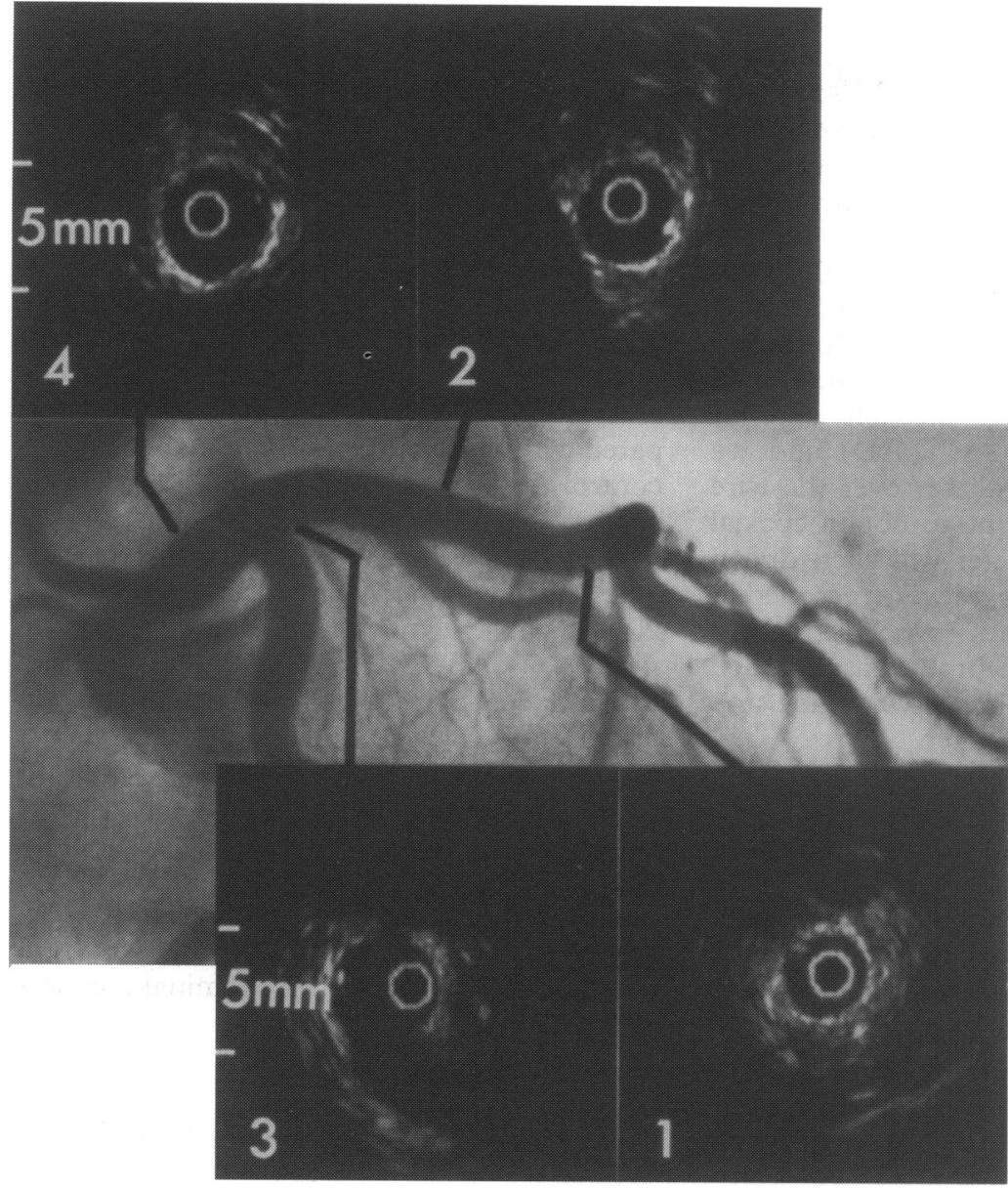

Figure 1 Angiogram and IVUS images at corresponding sites of LCA. No abnormalities were shown by either angiography or IVUS.

plaque in the ostium of the left main coronary artery (fig 4). This finding and the abnormal exercise ECG prompted bypass surgery in this patient.

CORRELATION BETWEEN DIMENSIONS

MEASURED BY ANGIOGRAPHY AND BY IVUS

For lumen diameter the intraobserver correlation for 30 IVUS images was $r=0.99$ (SEE
$0.16 \mathrm{~mm}$ ) and the interobserver correlation was $r=0.99$ (SEE $0.17 \mathrm{~mm}$ ). For lumen cross sectional area the intraobserver correlation was $r=0.99\left(\operatorname{SEE~} 1.39 \mathrm{~mm}^{2}\right)$ and interobserver correlation was $r=0.98$ (SEE 1.81 $\mathrm{mm}^{2}$ ).

The lumen diameter measured at 341 normalities was $2 \cdot 7-7.6 \mathrm{~mm}$ by IVUS and $2 \cdot 6-7 \cdot 3 \mathrm{~mm}$ by angiography. Linear regression of the lumen dimensions measured at 100 randomly selected sites showed a close correlation between IVUS and angiography for both lumen diameter and area (fig 5A and $\mathrm{B}$ ).

\section{NORMAL VALUES OF THE LEFT CORONARY} ARTERY

Sixteen ( 8 men and 8 women, aged 42-68 (mean (SD) $53.6(7 \cdot 4)$ ) of the 30 patients in whom no plaques in the LCA were detected by IVUS and who had no risk factors for coronary artery disease including systemic hypertension, cigarette smoking, hypercholesterolaemia, and diabetes mellitus were deemed to be truly normal subjects after their negative IVUS examination. Table 1 lists the clinical characteristics of the patients. The cross sectional area of the lumen in group I, who were regarded as normal subjects, was measured frame-by-frame for three to five cardiac cycles. The mean (SD) cross sectional areas of LMCA, proximal LAD, and mid LAD at end diastole (at the beginning of QRS complex) were $17.33 \quad(7.98) \mathrm{mm}^{2}$

Table 1 Clinical characteristics of the study population

\begin{tabular}{lccl}
\hline Characteristic & $\begin{array}{l}\text { Group I } \\
(n=16)\end{array}$ & $\begin{array}{l}\text { Group II } \\
(n=14)\end{array}$ & $\begin{array}{l}\text { Group III } \\
(n=25)\end{array}$ \\
\hline Age (yrs) (mean (SD)) & $53 \cdot 6(7 \cdot 4)$ & $55 \cdot 9(8 \cdot 0)$ & $58 \cdot 8(6 \cdot 6)$ \\
Men/women & $8 / 8$ & $4 / 10$ & $16 / 9$ \\
Positive rest ECG & $2 / 16$ & $12 / 14$ & $17 / 25$ \\
Positive stress ECG & $7 / 16$ & $9 / 13$ & $12 / 19$ \\
Positive thallum test & $6 / 11$ & $2 / 4$ & $9 / 11$ \\
\hline
\end{tabular}

Group I = No plaques detected by IVUS and no risk factors for coronary artery disease. Group II = No plaques detected by IVUS; patients had risk factors for coronary artery disease. Group III = Plaques detected by IVUS

Figure 2 IVUS images of eccentric plaques showing calcified deposits as bright echoes with acoustic shadowing (arrows).

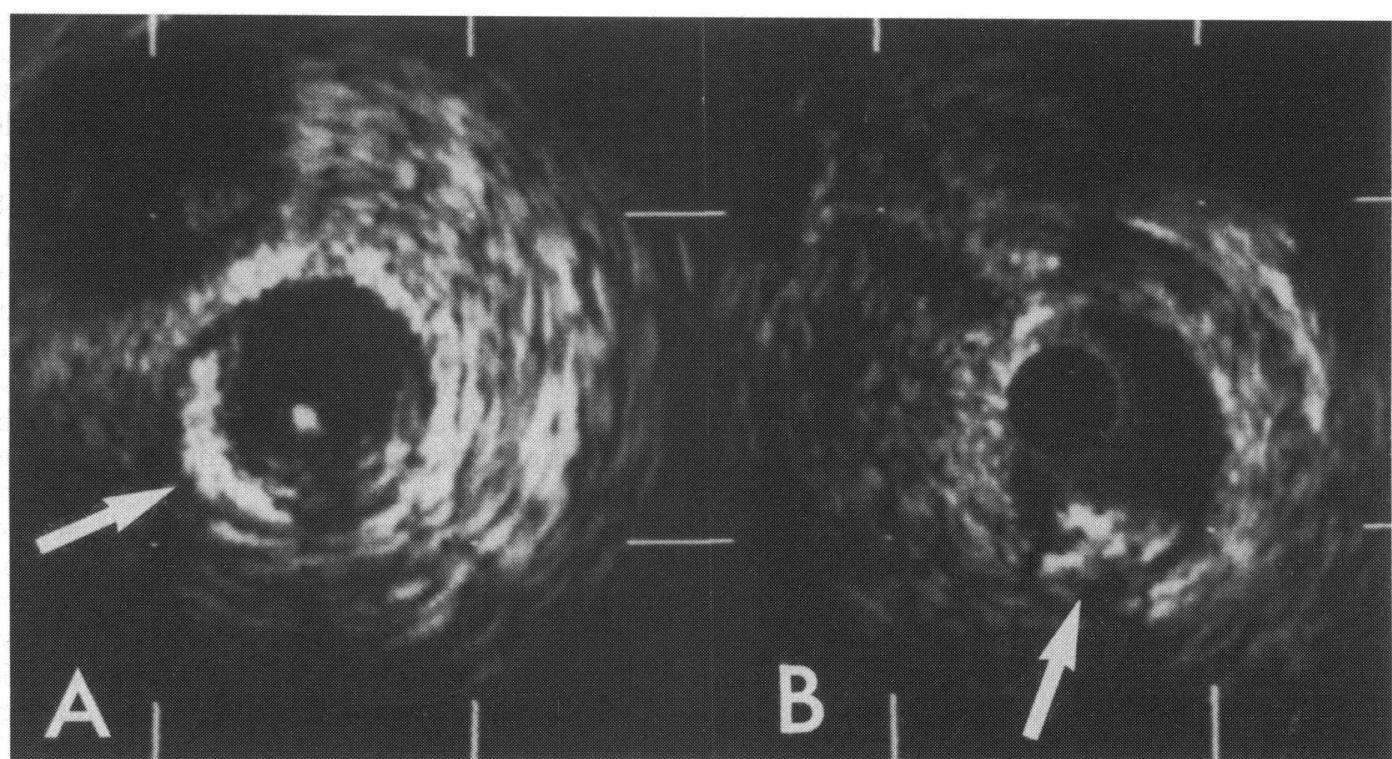


Figure 3 Comparison of an angiogram, showing no abnormality, and IVUS

images showing eccentric

plaques in the LMCA

(position 5) and mid LAD

(position 2) in one patient.
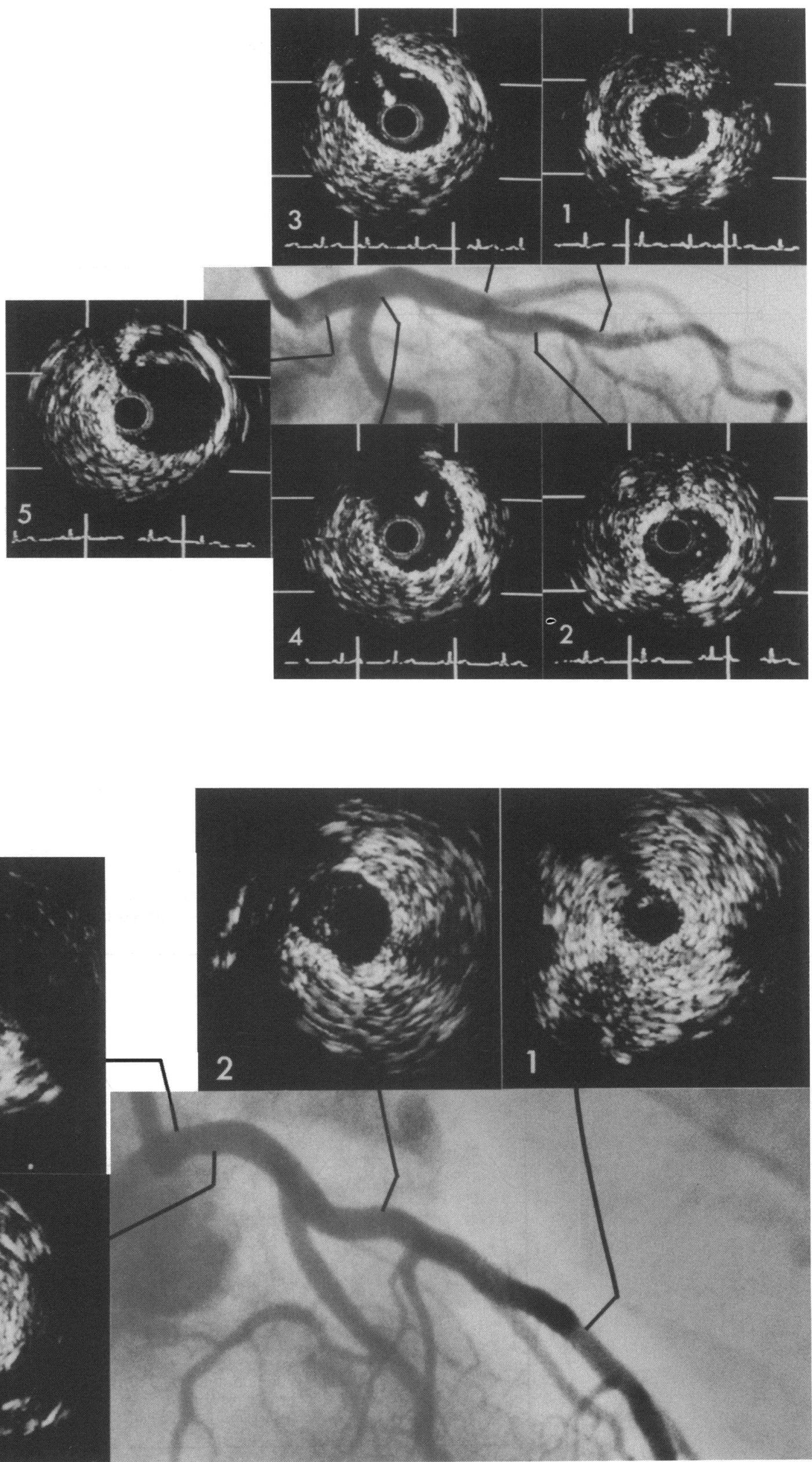

Figure 4 In this 50 year old patient the angiogram was normal but IVUS showed a large eccentric plaque in the ostium (position 3 and 4). 

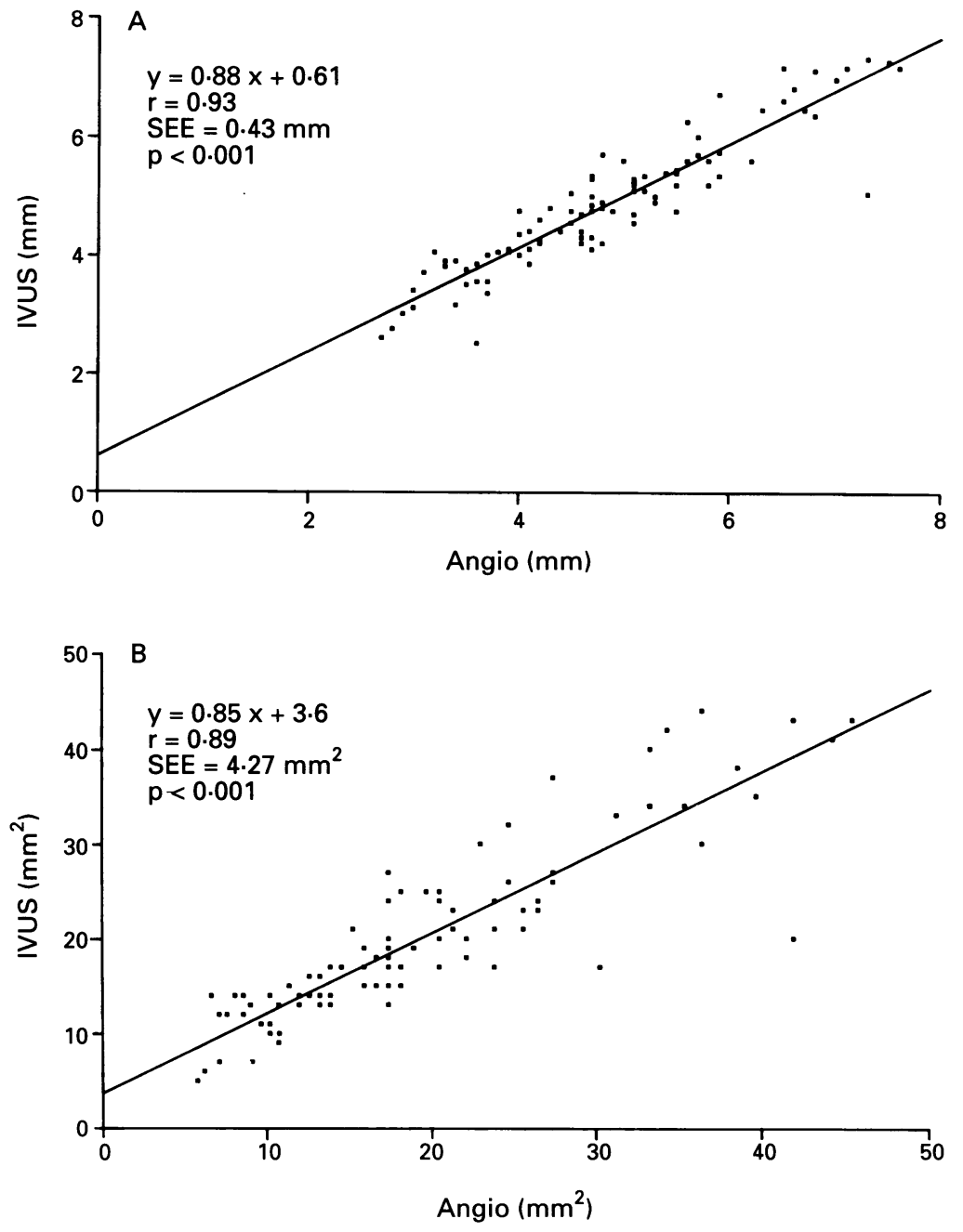

Figure 5 Relation between angiographic (Angio) and ultrasonic measurements (IVUS) of lumen dimensions at normal sites. (A) Lumen diameter; (B) lumen area. (range $9 \cdot 12-30 \cdot 71), 13 \cdot 56(5 \cdot 85) \mathrm{mm}^{2}$ (range 6.42-20.05), and $9 \cdot 75(4 \cdot 67) \mathrm{mm}^{2}$ (range 4.53-22.01). The maximum areas and the end diastolic areas were significantly different (table 2).

PUSATILE VARIATION IN THE CROSS SECTIONAL AREA OF THE LUMEN

The pulsatile variations during the cardiac cycle of the normal patients were $10 \cdot 2(4 \cdot 0) \%$ in LMCA, $8 \cdot 3(4.7) \%$ in the proximal LAD, and $9 \cdot 8(4 \cdot 0) \%$ in mid LAD. Figure 6 shows the changes in cross sectional area on 90 consecutive frames of 3 to 5 cardiac cycles in the LMCA, the proximal LAD, and the midLAD. The pulsatile variation in 11 patients with plaques $(5 \cdot 8(3 \cdot 1) \%)$ was much lower than in segments in the normal group $(\mathrm{p}<$ 0.001 ) (fig 7).

\section{Discussion}

Davidson et al reported that IVUS might be useful in demonstrating angiographically "silent" plaques. ${ }^{11}$ Davies et al used IVUS to show a left main stem stenosis in a patient who had chest pain at rest but no angiographic evidence of stenosis. ${ }^{16}$ The case shown in fig 4 resembles the case reported by Davies et al. We found atherosclerotic plaques in the LCA at $17 \%$ of the angiographically normal sites in $46 \%$ of our patients. These results suggest that IVUS can provide evidence of coronary atherosclerosis in patients with symptoms who have normal or inconsistent angiographic findings. None the less, a cause and effect relation cannot be assumed. Such a relation is more likely, however, when there is corroborating functional evidence of ischaemia from stress echocardiography and thallium scintigraphy or evidence of impaired coronary flow reserve. Moreover, IVUS gives information about the plaque characteristics
Figure 6 Pulsatile variation in the cross sectional area of the LMCA $(A)$, proximal $L A D(B)$, and of the mid $L A D$ (C) in 90 consecutive frames.

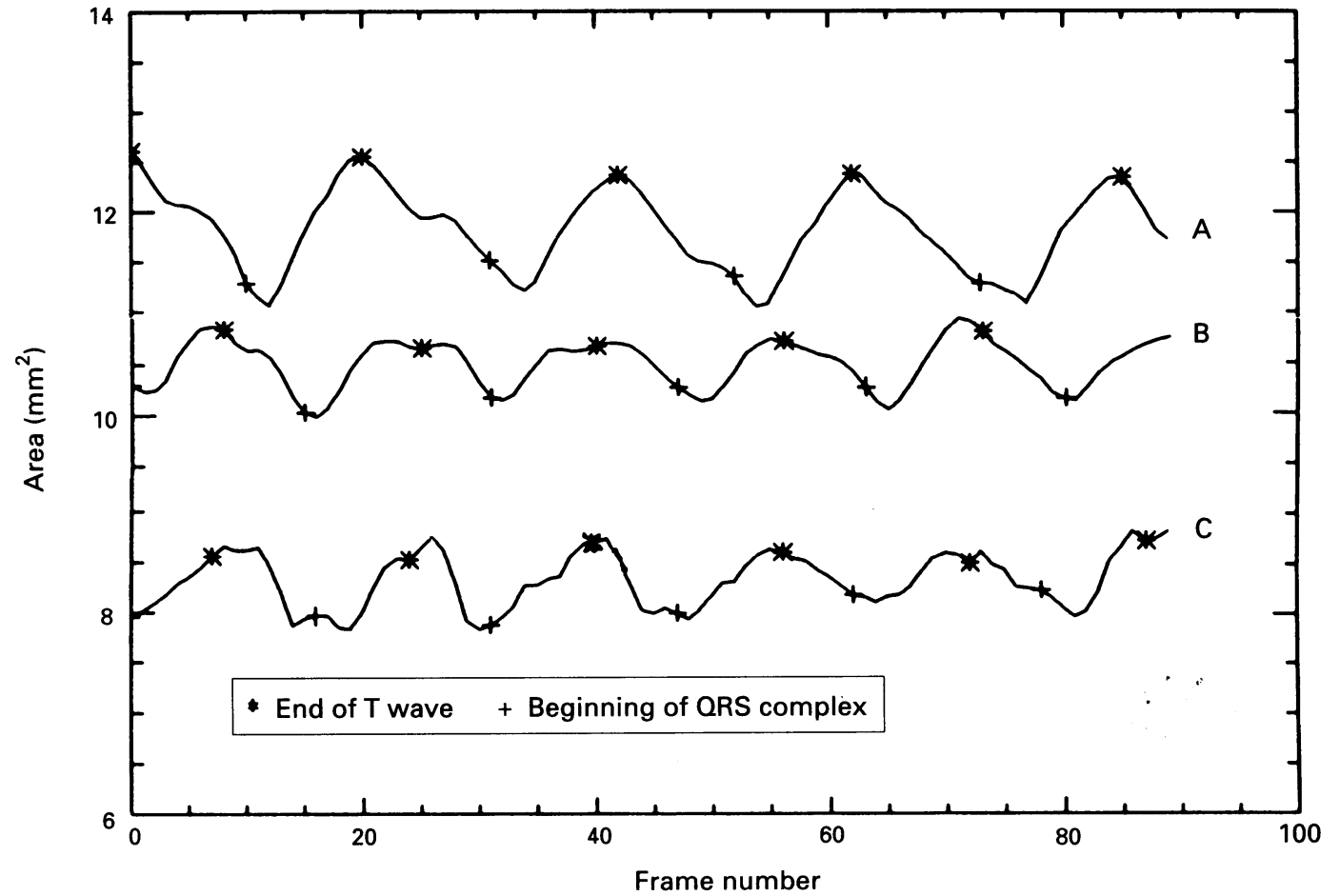



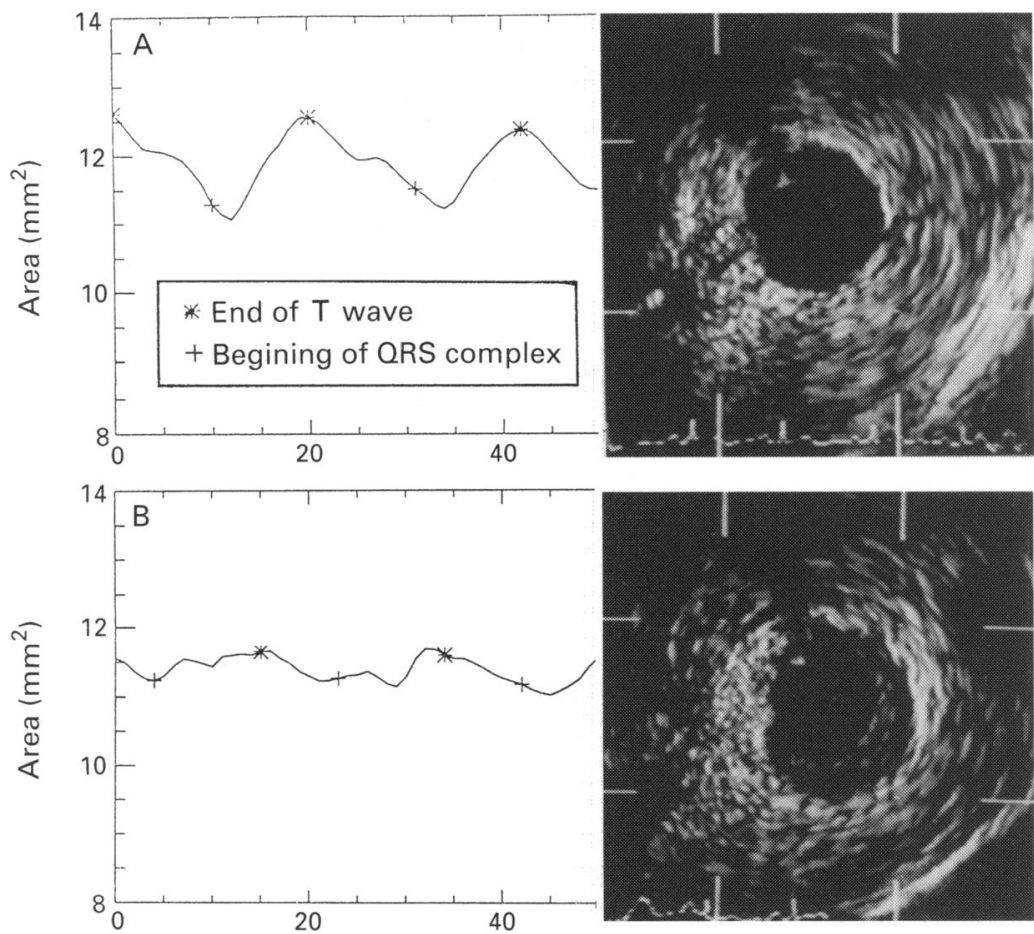

Figure 7 Comparison of the pusatile variation of the cross sectional area of a normal $(A)$ coronary artery and of a coronary artery with an eccentric plaque (B).

(concentric, eccentric, calcified). These findings might be helpful for patient management and predicting prognosis.

Preliminary in vitro studies showed a close correlation between intravascular ultrasonic and anatomical measurements of vessel dimensions, ${ }^{12-14}$ but results of in vivo studies were not consistent. ${ }^{9-1115}$ Davidson et al reported that the correlation coefficients between ultrasonographic and digital subtraction angiographic measurements were 0.97 for vessel diameter and 0.95 for vessel area. ${ }^{11}$ Nissen et al and $\mathrm{Ge}$ et al reported similar results. ${ }^{1015}$ On the other hand, Tobis et al reported a correlation coefficient of 0.26 for IVUS and angiographic measurements for vessel area. ${ }^{9}$ In the present study, however, there was a close correlation between IVUS and angiographic measurements for lumen diameter and area at normal sites $(r=0.93$, SEE $=0.43 \mathrm{~mm}, \mathrm{p}<0.001 ;$ and $\mathrm{r}=0.89$, SEE $=4.27 \mathrm{~mm}^{2}, \mathrm{p}<0.001$, respectively). An experimental study in our laboratory showed that incorrect programming of the IVUS device can result in misrepresentation of vessel dimensions. ${ }^{17}$ The poor correlation between IVUS and angiographic measure-

Table 2 Cross sectional areas of normal LCA during cardiac cycle (mean (SD))

\begin{tabular}{|c|c|c|c|c|}
\hline & $\begin{array}{l}\text { Maximum } \\
\left(\mathrm{mm}^{2}\right)\end{array}$ & $\underset{\left(m m^{2}\right)}{\operatorname{Minimum}}$ & $\begin{array}{l}\text { End diastole } \\
\left(\mathrm{mm}^{2}\right)\end{array}$ & $\begin{array}{l}\text { Pulsation } \\
(\%)\end{array}$ \\
\hline $\begin{array}{c}\text { LMCA } \\
\text { Range }\end{array}$ & $\begin{array}{r}18.33(8 \cdot 18) \\
9 \cdot 74-36 \cdot 02\end{array}$ & $\begin{array}{c}16.49(6.77)^{\star} \\
8.83-29.95\end{array}$ & $\begin{array}{c}17 \cdot 33(7 \cdot 98)^{\star} \\
9 \cdot 12-30 \cdot 71\end{array}$ & $10 \cdot 2(4 \cdot 0)$ \\
\hline Proximal LAD & $14.01(5.54)$ & $12.95(5.08)^{\star}$ & $13.56(5.85) \dagger$ & $8 \cdot 3(4 \cdot 7)$ \\
\hline Range & $6.91-26.21$ & $6 \cdot 34-23 \cdot 61$ & $6 \cdot 42-26 \cdot 10$ & \\
\hline Mid LAD & $10 \cdot 70(4 \cdot 47)$ & $9 \cdot 78(4 \cdot 24)^{\star}$ & $9.75(4.67)^{\star}$ & $9 \cdot 8(4 \cdot 0)$ \\
\hline Range & $4 \cdot 78-22 \cdot 74$ & $4 \cdot 49-21 \cdot 47$ & $4.53-22 \cdot 01$ & \\
\hline
\end{tabular}

ments in vivo might be caused by (a) difficulties in using the catheter tip to calibrate for quantitative angiography; (b) difficulties in matching the sites measured by IVUS and angiography; (c) assessment of coronary dimensions in different phases of the cardiac cycle; and $(d)$ errors resulting from incorrect software calibration of the IVUS device.

The dimensions of normal human coronary arteries have been measured in several postmortem studies; some of the measurements were obtained from sections made using pressure perfusion techniques. ${ }^{18-20}$ However, postmortem measurements may not accurately reflect coronary dimensions during the cardiac cycle. ${ }^{20}$ Data on the normal values of coronary arteries in living subjects are limited and all are based on coronary angiography. ${ }^{21-23}$ Area determination by quantitative angiography does not take account of the marked luminal irregularities sometimes found in diseased coronary arteries. We found that $17 \%$ of the angiographically normal sites in coronary arteries were not really normal. Moreover, the lumen dimensions varied during the cardiac cycle. We suggest that the dimensions obtained by IVUS are more accurate than those measured by angiography and postmortem studies. We showed that the cross sectional area of the lumen reached a maximum in early diastole. This accords with studies of the circumflex coronary artery in anaesthetised dogs. ${ }^{24}$ The change in the cross sectional area of the lumen of normal coronary arteries during the cardiac cycle was $10 \cdot 2$ $(4.0) \%$ in the LMCA, $8.3(4.7) \%$ in the proximal LAD, and $9 \cdot 8(4 \cdot 0) \%$ in the mid LAD. This change in area was much less in segments containing plaques in 11 patients with atherosclerosis. IVUS detected atherosclerosis in almost half of the patients in our study with normal angiograms. The clinical implication of these results remains to be clarified by longterm clinical follow up. Repeat catherisation and IVUS may well provide important pathophysiological and clinical information in patients with evidence of continuing coronary ischaemia.

We also measured the pulsatile variation in cross sectional area during the cardiac cycle. We established that this variation is too large to be ignored when these dimensions are measured. This finding shows that the pulsatile variation in dimensions must be taken into account when measurements derived from the IVUS image are compared with other imaging methods. Moreover, the pulsatile variation of the cross sectional area may offer a new index in evaluating the vascular function.

\section{LIMITATIONS OF THE STUDY}

With IVUS, as with transthoracic $M$ mode or cross sectional echocardiography, the cardiac cycle causes the portion of the transducer on the chest wall to move in relation to the heart. We found that although the position of the IVUS catheter was fixed by the " $Y$ " adaptor and guidewire, its position in relation to the vessel wall probably changed during the cardiac cycle. Thus the pulsatile variation of 
the vessel lumen may be affected by a shift in the frame caused by cardiac events. Furthermore, long term follow up study will be needed to analyse the clinical significance of the plaques detected by ultrasound. We used a $20 \mathrm{MHz}$ transducer. New studies showed that transducers with higher frequency may improve the resolution ${ }^{25}$ and may provide further insights into the atherosclerotic process.

We thank Mrs Ruth Katz, Dr Thomas Roth, and Dr Peter Kearney for help with preparing this paper.

1 Grondin CM, Dyrada I, Pasternac A, Campeu L, Bourassa MG, Lesperance J. Discrepancies between cineangiographic and postmortem findings in patients with coronary artery disease and recent myocardial revasculization. Circulation 1974;49:703-13.

2 Eusterman JH, Achor RWP, Kincaid OW, Brown Al Jr. Atherosclerotic disease of the coronary arteries: A pathologic-radiologic study. Circulation 1962;26:1288-95.

3 White CW, Wright CB, Doty DB, Hiratzka LF, Eastham CL, Harrison DG, et al. Does visual interpretation of the coronary angiograms predict the physiologic importance of the coronary stenosis? $N$ Engl $¥ \mathrm{Med} 1984 ; 310$ : 819-24.

4 Vlodaver $Z$, French $R$, van Tassel RA, Edwards JE. Correlation of the antemortem coronary angiogram and the postmortem specimen. Circulation 1973;47:162-8.

5 Isner JM, Kishel J, Kent KM. Accuracy of angiographic determination of the left main coronary arterial narrowing. Circulation 1981;63:1056-61.

6 Hodgson JM, Graham SP, Savakus AD, Dame SG, Stephens DN, Dhillion D, et al. Clinical percutaneous imaging of coronary anatomy using an over-the-wire imaging of coronary anatomy using an over-the-wire ultrasou.

7 Bartorelli AL, Potkin BN, Almagor Y, Keren G, Roberts WC, Leon MB. Plaque characterization of atherosclerotic coronary arteries by intravascular ultrasound. Echocardiography 1990;7:389-95.

8 Siegel RJ, Chae JS, Forrester JM, Ruiz CE. Angiography, angioscopy, and ultrasound imaging before and after percutaneous balloon angioplasty. Am Heart f 1990;120: 1086-90.

9 Tobis JM, Mallery J, Mahon D, Lehmann K, Zalesky P, Griffith J, et al. Intravascular ultrasound imaging of human coronary arteries in vivo. Circulation $1991 ; 83$ 913-26.
10 Nissen SE, Gurley JC, Grines CL, Booth DC, McClure R, Berk $M$, et al. Intravascular ultrasound assessment of lumen size and wall morphology in normal subjects and patients with coronary artery disease. Circulation 1991; 84:1087-99.

11 Davidson CJ, Sheikh KH, Harrison JK, Himmelstein SI, Leithe ME, Kisslo KB, et al. Intravascular ultrasonography versus digital substraction angiography. F Am

12 Ge J, Erbel R, Seidel I, Görge G, Reichert T, Gerber T, $e t$ al. Experimental evaluation of accuracy and safety of intraluminal ultrasound. $Z$ Kardiol 1991;80:595-601.

13 Nishimura RA, Edwards WD, Warnes CA, Reeder GS Holmes DR Jr, Tajik AJ, et al. Intravascular ultrasound imaging: in vitro validation and pathologic correlation. imaging: in vitro validation and pall Cardiol 1990;16:145-54.

14 Pandian NG, Kreis A, Brokway B, Isner JM, Sachroff A Boleza E, et al. Ultrasound angioscopy: real-time, twoBoleza E, et al. Ultrasound angioscopy: real-time, two-
dimensional, intraluminal ultrasound imaging of blood vessels. $A m f$ Cardiol 1988;62:493-94.

15 Ge J, Erbel R, Görge G, Gerber T, Meyer J. Intravascular ultrasound imaging of angiographically normal coronary arteries. Z Kardiol 1992;81 (abstr): 152

16 Davies SW, Winterton SJ, Rothman MT. Intravascular ultrasound to assess left main stem coronary artery lesion. Br Heart $\mathcal{f}$ 1992;68:524-6.

$17 \mathrm{Ge} J$, Erbel R, Trautmann S, Gerber T, Seidel I, Brennecke $R$, et al. Influence of catheter design on the accuracy of ultrasound. Eur Heart f 1992;13(abstr):394

18 Ehrlich W, de la Chapelle C, Cohn AE. Anatomica ontogecy: A study of the coronary arteries. Am $\mathcal{F} A n a$ 1931;49:241-82.

19 Hutchins GM, Bulkley BH, Miner MM, Boitnott JK. Correlation of age and heart weight with tortuosity and caliber of normal human coronary arteries. Am Heart $f$ 1977;94:196-202.

20 Rodriguez FL, Robbins SL. Capacity of human coronary arteries: A postmortem study. Circulation 1959;19: 570-78.

21 Leung WH, Stadius ML, Alderman EL. Determinations of normal coronary artery dimensions in humans. of normal coronary artery

22 MacAlpin RN, Abbasi AS, Grollman JH, Eber L. Human coronary artery size during life: A cinearteriographic coronary artery size during life:
study. Radiology 1973;108:567-76.

23 Vieweg WVR, Alpert JS, Hagan AD. Caliber and distribution of normal coronary arterial anatomy. Cathet Cardiovasc Diagn 1976;2:269-80.

24 Spears RJ, Sandor T. Quantitation of coronary artery stenosis severity: Limitations of angiography and computerized information extraction. In: Reiber JHC, Serruys PW, eds. State of the art in quantitative coronary arteriography: Martinus Nijhoff, 1986:103-24.

25 Lockwood GR, Ryan LK, Gotlieb AI, Lonn E, Hunt JW, Liu P, Foster FS. In vivo high resolution intravascular imaging in muscular and elastic arteries. $\mathcal{f} \mathrm{Am}$ Coll Cardiol 1992;20:153-60. 